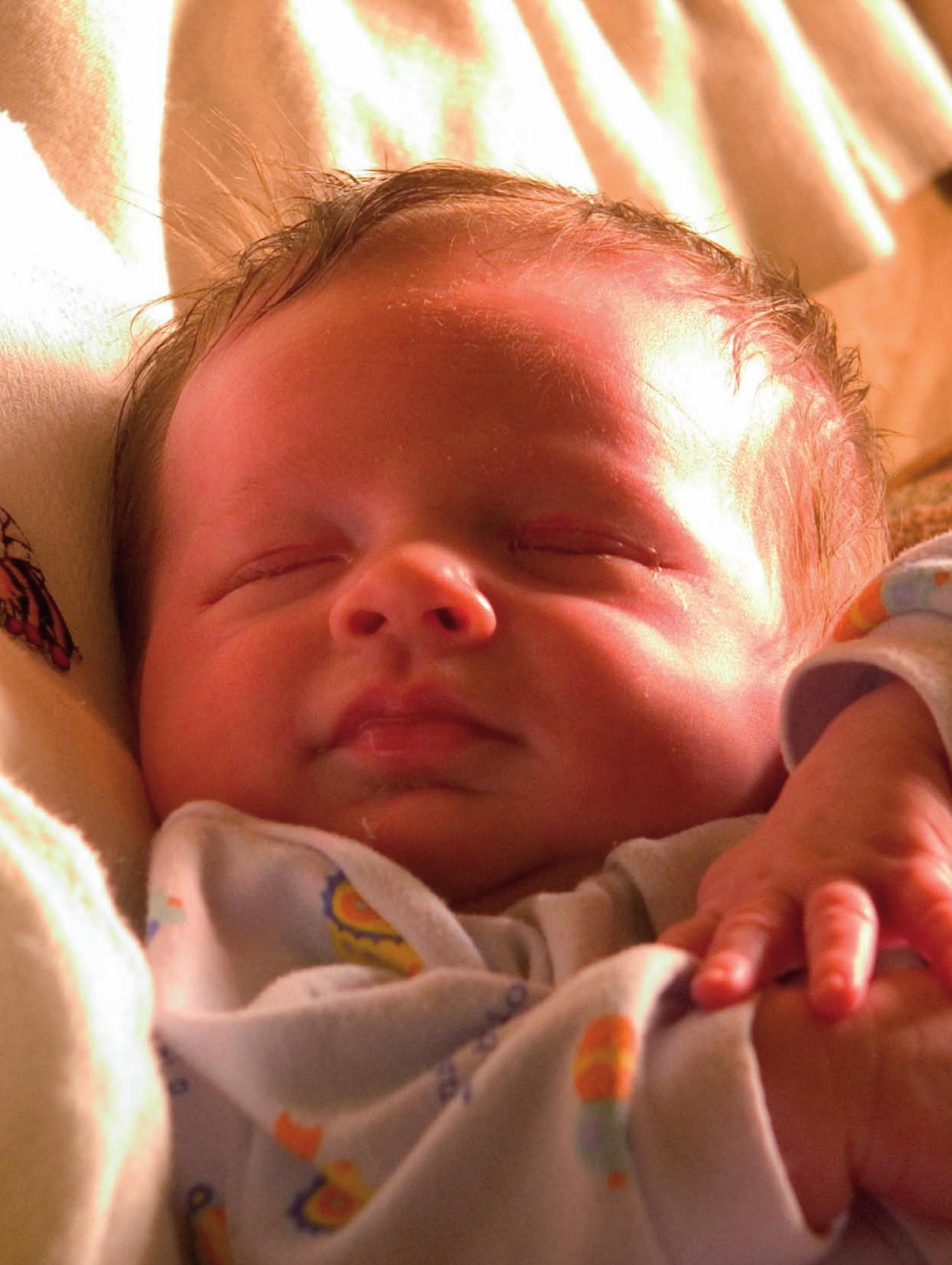




\section{Bronchiolitis in infants and wheeze in preschool children}

\section{Introduction}

Bronchiolitis (table 1) is one of the main causes of hospitalisation in infants aged $<1 \mathrm{yr}$ [1]. Approximately 2-3\%, without underlying diseases, are hospitalised for bronchiolitis during epidemics. Recently the number of the hospital admission has increased, with the use of pulse oximetry possibly contributing to the higher admission rate [2]. Respiratory syncytial virus (RSV) infection is the most common cause of severe bronchiolitis [3]. The incidence peaks in December-March. Nearly all children are infected by RSV before the age of 2 [1], usually reporting only a mild upper respiratory tract infection. In some cases, lower respiratory symptoms leading to respiratory failure characterise the clinical course of bronchiolitis. Many risk factors have been found to be associated with the severity of the disease, but the reason why viruses cause lower respiratory infection and consolidation only in some children is still unknown.

Recently, respiratory viruses other than RSV have been detected in infants with bronchiolitis. Rhinovirus (RV), the major cause of the common cold, was considered to be confined in the upper respiratory tract. Nowadays, RV seems to be as common as RSV, often affecting older children, and those with atopic dermatitis and eosinophilia [4].

The treatment is mainly supportive [5], with supplemental oxygen, nasal washing, i.v. fluids and, in some cases, mechanical ventilation.
Clinical trials, testing $\beta 2$-agonists $[6,7]$, glucocorticoids [8], epinephrine [9], recombinant human DNase [10, 11] and hypertonic saline [12] in bronchiolitis have been very controversial. Routine use of those different therapies is not recommended. On the contrary, a personalised strategy for each infant is to be performed, in order to reduce hospital stay and health-care expenditures associated with this disease.

\section{Diagnosis}

Bronchiolitis is a clinical diagnosis requiring epidemiologic data, such as the epidemic period (December-March), the age of infants (age $<12$ months) and the specific clinical appearance. It is usually characterised by runny nose, fever and cough, preceding respiratory distress, with possible tachypnoea and retractions.

The various auscultatory findings required for diagnosis have complicated the interpretation of clinical, therapeutic and epidemiological studies on bronchiolitis. In fact, the inclusion of wheeze in the diagnostic criteria by North American physicians can overlap the bronchiolitis with early presentation of asthma. Otherwise, the presence of respiratory crackles, as the most important clinical finding, permits a correct diagnosis of bronchiolitis.

Most infants with bronchiolitis present a mild clinical form and can be safely managed at home by compliant parents, if adequately informed on the signs of deterioration of the
F. Midulla

R. Nenna

Department of Paediatrics, "Sapienza" University of Rome, Rome

Italy

\section{Correspondence}

F. Midulla

Department of Paediatrics

"Sapienza" University of Rome

V.le Regina Elena 324

00161

Rome

Italy

midulla@uniroma1.it

\section{Competing interests}

None declared.

\section{Table 1 Definition of bronchiolitis}

First acute lower respiratory tract infection

\section{Age}

Epidemic period

Clinical examination
$<12$ months

December-March

Tachypnoea, respiratory crackles, retractions 
clinical status. On the contrary, infants with risk factors, such as prematurity, young age, small weight, male sex, underlying medical conditions, more frequently need the hospitalisation. Usually the disease is characterised by a worsening over the first $72 \mathrm{~h}$. This factor must be considered in the management of infants with bronchiolitis. Only $1-3 \%$ of infants require the admission to intensive care, particularly when risk factors are present [13].

\section{Virus and bronchiolitis}

Normally affecting $\leqslant 75 \%$ of infants with bronchiolitis, RSV remains the most common isolated virus. Moreover, cases of bronchiolitis increase during RSV peak [14].

RV follows RSV in incidence, with also other viruses involved in bronchiolitis, such as human metapneumovirus (hMPV) [15], human bocavirus [16], enterovirus, adenovirus, influenza virus, human coronavirus and parainfluenza virus. Sometimes these viruses are found in coinfection with RSV or RV. The incidence of RV peaks in spring and autumn.

Even though the association between virus involved and clinical severity is still debated [17-22], RSV seems to cause a more severe disease [21], particularly when the dual infection $\mathrm{RSV}+\mathrm{hBoV}$ is present [22]. Also, the viral load could influence the severity of bronchiolitis $[23,24]$. Instead, RVs cause a milder form of bronchiolitis than RSV [22]. Bacterial co-infection is rarely described in infants with bronchiolitis, often reported in more severe diseases $[13,25]$.

\section{From bronchiolitis to wheezing bronchitis}

Infants aged $<6$ months at the beginning of the winter season are at high risk for recurrent wheeze. Furthermore, infants with early and severe bronchiolitis, who have required hospital admission, are at significantly higher risk for both recurrent wheeze and subsequent asthma [26]. This association, which has been known for more than 50 years [27], is well documented in RSV bronchiolitis [26] but, recently, the role of other viruses, particularly RV, was demonstrated [22].

The association between bronchiolitis and wheeze is not surprising, considering the crucial role of viral infections in asthma exacerbations and in altering the pattern of Thelper cell (Th) type 1/ type 2 response, although the underlying factors that could explain this association are not yet understood. In particular, it is not clear which viral infections predispose to asthma, possibly by modifying the host, or when respiratory viruses identify infants who are themselves predisposed to develop asthma.

Some studies have demonstrated that infants with early alteration of lung function more likely develop bronchiolitis [28, 29]. Otherwise, in animal models, changing in neurogenic control of the airway, mainly mediated by an upregulation of the substance $P$, was demonstrated after RSV infection [30, 31]. Bronchial hyperresponsiveness lasts long and could explain the occurrence of wheezing later in life. Moreover, the chronic inflammation could cause the shrinkage of the airway in children, also many years after RSV infection. On the other hand, VRS-specific immunoglobulin (Ig)E has been found in infants with bronchiolitis, and experimental evidence shows that early RSV infection may result, in selected individuals, in a Th-2 immune response, thus predisposing these children to asthma [32, 33]. In conclusion, infants in the first months of life, with severe bronchiolitis and a Th-2 immune response, will possibly develop wheeze or asthma [33] (fig. 1). Unfortunately, according to this hypothesis, it is not clear whether the virus predisposes to this immune response or the virus infects children already destined for a Th-2 response.

Nowadays, a cytokine dysregulation has been widely demonstrated [34-37], but the specific biological, therapeutic and prognostic significance in infants with bronchiolitis is not completely understood and it could probably explain the link between viral infection and childhood asthma. Almost all elements of the immune system are involved in the immunopathogenesis of bronchiolitis. In particular, alveolar macrophages play a crucial role in RSV infection, by replicating the virus but, at the same time, they are activated by virus infection, thus triggering the immune response [35]. During infection, the epithelium and leukocytes release cytokines that amplify the inflammation (fig. 2).

Many retrospective studies [38-44] have demonstrated that severe bronchiolitis, requiring hospitalisation, is an independent risk factor for subsequent wheeze, in terms of parentreported wheeze [38], use of bronchodilators [39] and doctor-diagnosed asthma [40]. A recent paper, performed in a small series of infants with early severe RSV bronchiolitis (46 children), showed that RSV infection was an important risk factor 
for the development of asthma, clinical allergy and sensitisation to common allergens at the age of 18 yrs [41]. In long-term follow-up studies $[43,44]$, a higher asthma prevalence at late teenage in both RSV and non-RSV bronchiolitis infants was found, thus suggesting a possible host factor in developing future asthma. Moreover, the findings that reduced interferon production in early life predicts later recurrent wheezing $[45,46]$, seems to confirm the role of host factor.

According to some studies, RV is the most frequent virological agent in infants with both upper and lower respiratory infections. This observation was confirmed in two birth cohort studies, both in 197 unselected infants [47] and in 263 infants with risk factors for atopic sensitisation [48]. JACKSON et al. [49] evaluating 289 newborns at risk for atopy up to the age of $6 \mathrm{yrs}$, found that moderate-to-severe RV wheez ing illness was the most significant risk factor not only for the development of preschool wheezing at the age of 3 yrs, but also for the development of asthma at the age of 6 yrs. Similar results were found in 82 infants below the age of $2 \mathrm{yrs}$, hospitalised for wheezing and followed for 6 yrs. This study confirmed that RV- induced wheezing during infancy was an early predictor of the subsequent development of asthma [50].

In a 3-yr follow-up retrospective study on 144 infants (aged 4-6 months) with bronchiolitis, VALKONEN et al. [51] showed that recurrent wheezing develops at substantially higher rates in children hospitalised with bronchiolitis caused by viruses other than RSV with respect to children with RSV-induced bronchiolitis. In that study, the non-RSV bronchiolitis infants were not characterised further, but possibly RV, which remains the most important viral agent following RSV [22], played an important role.

In a recent paper, 182 infants with bronchiolitis were tested for 14 respiratory viruses on pharyngeal swabs or nasal aspirates, using a panel of real-time reversetranscriptase-polymerase-chain-reaction (RT-PCR) or nested PCR assays. A virus was identified in only $57.2 \%$ of patients, while most of the remaining negative infants were possibly infected by undetected pathogens. In that study, three groups of infants were individuated, according to the viral agent, which reflects different demographic characteristics. In fact, infants with RSV bronchiolitis $(41.2 \%)$ were younger, had been breast fed for a shorter time and developed a more severe form of the disease with prevalent

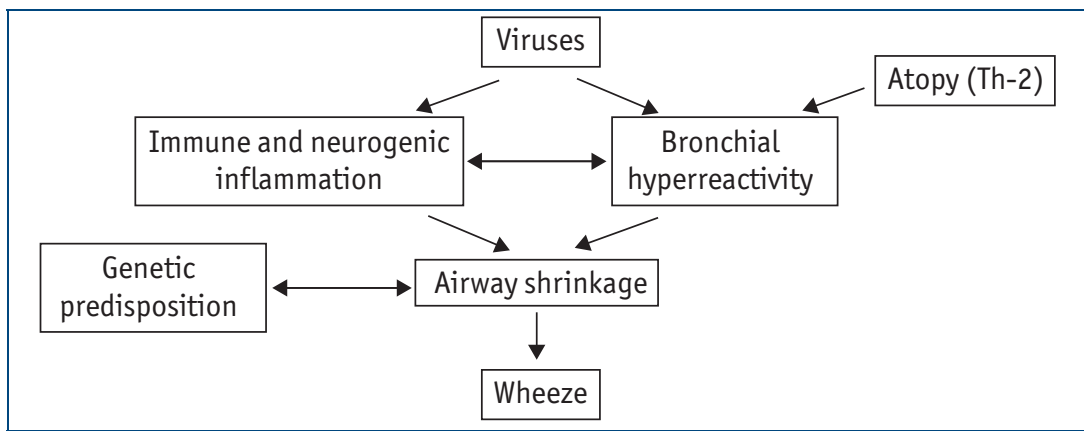

Figure 1

Factors influencing wheeze development in infants with bronchiolitis.

diffuse air trapping on the chest radiograph. Conversely, infants with hBoV bronchiolitis $(12.2 \%)$ were the oldest, had been breast fed for longer and had the mildest clinical form, with patchy infiltrates on the chest radiograph. Instead, RV bronchiolitis (8.8\%) showed an intermediate form of bronchiolitis. It is worth noting that the latter group of infants had a more frequent family history for atopy and higher blood eosinophil counts than others. These findings seem to suggest that RV preferentially infects infants who are predisposed to asthma [22].

A recent paper evaluated "recurrent wheezing", defined as two or more physician-verified episodes of wheezing during a 1-yr follow-up, at 12 months after discharge, in 262 infants hospitalised for bronchiolitis in the first year of life. It was demonstrated that the major risk factors for wheezing episodes after acute bronchiolitis were RV infection and a positive heredity for asthma. Moreover, a higher number of blood eosinophils, a lower blood CRP concentration and fewer radiologically

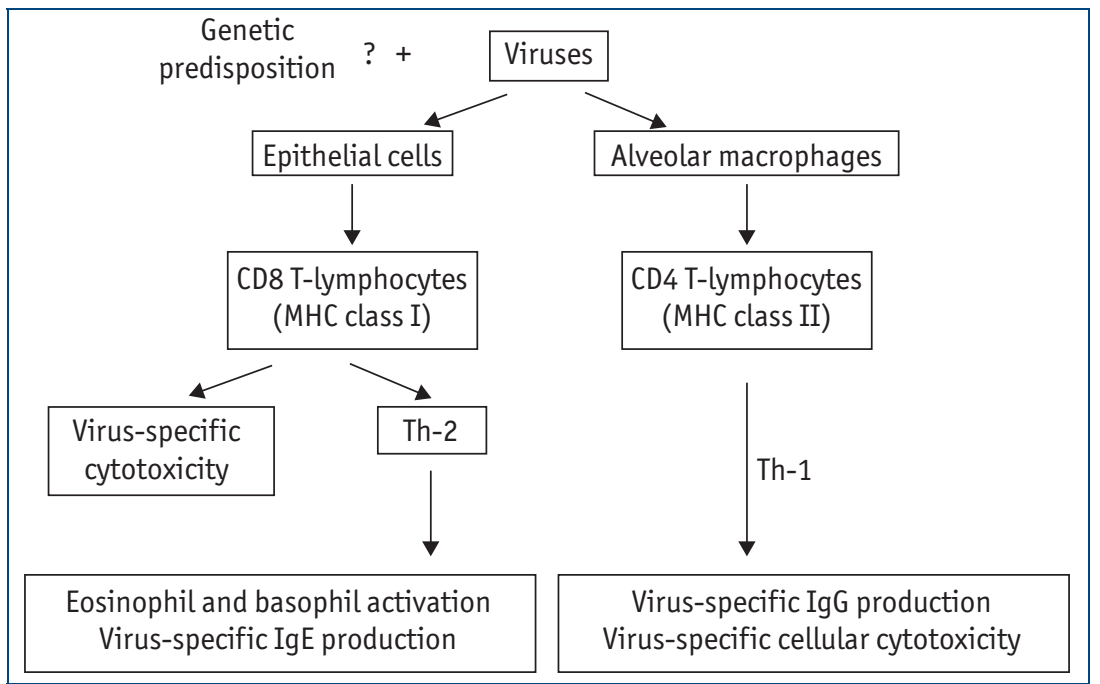

Figure 2

Immunological mechanisms involved in lung injury by viruses. 
documented lung consolidations in infants with recurrent wheezing than non-wheezing infants were found [52]. Finally, a slightly higher frequency of wheezing in boys was demonstrated and could be partially explained by the knowledge of high airway resistance in male infants and low functional residual capacity in female infants [28].

According to LeHTINEN et al. [53], RV infants who received oral corticosteroid therapy during the acute severe viral episode, are less likely to develop recurrent wheezing over the following year. This finding could suggest a distinct pathogenesis and consequently a distinct therapeutic approach for wheezing RV-positive infants.

Current knowledge therefore clearly links RV bronchiolitis and recurrent wheezing during the first year of life. It therefore raises the question of whether RV bronchiolitis actually causes recurrent wheezing. Alternately, RV bronchiolitis might instead serve to disclose infants, who are already predisposed to this disease owing to abnormal lung physiology or immune response, or both. In vitro findings seem to confirm that RV preferentially affects the lower airways causing bronchiolitis in atopic children prone to wheeze [54-56]. In a study designed to investigate the balance between type 1 and type 2 immune response to
RV, Papadopoulos et al. [57] found that peripheral blood mononuclear cells (PBMCs) incubated with RV from atopic subjects produced interleukin-10 whereas PBMCs from nonatopic subjects produced interferon- $\gamma$ and interleukin12. This defective type 1 immune response to RV in predisposed patients with asthma may contribute to the development of acute asthma exacerbation by promoting type 2 inflammation and diminishing viral clearance through deficient type 1 antiviral immune response [57].

In conclusion, although the association between bronchiolitis and subsequent asthma has long been known, it is still unclear whether viral infection directly contributes for those children who are at risk for wheeze. RSV remains the most common pathogen associated with bronchiolitis, but other viruses have been linked to bronchiolitis, including rhinovirus, human metapneumovirus, influenza $A / B$, parainfluenza and human bocavirus. The most important aetiological agent in children with acute respiratory infections is RV in wheezing infants in the first years of life, which is an important risk factor for the development of asthma. Moreover, $\mathrm{RV}$ is an important risk factor for recurrent wheezing in infants hospitalised for bronchiolitis. These findings seem to confirm that we now need to switch our research efforts from RSV to RV.

\section{References}

1. Hall CB. Respiratory syncytial virus: A continuing culprit and conundrum. J Pediatr 1999; 135: 2-7.

2. Mallory MD, Shay DK, Garrett J, et al. Bronchiolitis management preferences and the influence of pulse oximetry and respiratory rate on the decision to admit. Pediatrics 2003; 111: e45-e51.

3. Smyth RL, Openshaw PJ. Bronchiolitis. Lancet 2006; 368: 312-322.

4. Korppi M, Kotaniemi-Syrjänen A, Waris M, et al. Rhinovirus-associated wheezing in infancy: comparison with respiratory syncytial virus bronchiolitis. Pediatr Infect Dis J 2004; 23: 995-999.

5. Wainwright C. Acute viral bronchiolitis in children: a very common condition with few therapeutic options. Paediatr Respir Rev 2010; 11: 39-45.

6. Alario AJ, Lewander WJ, Dennehy $P$, et al. The efficacy of nebulized metaproterenol in wheezing infants and young children. Am J Dis Child 1992; 146: 412-418.

7. Gadomski AM, Lichenstein R, Horton L, et al. Efficacy of albuterol in the management of bronchiolitis. Pediatrics 1994; 93: 907-1012.

8. van Woensel JB, Wolfs TF, van Aalderen WM, et al. Randomized double blind placebo controlled trial of prednisolone in children admitted to hospital with respiratory syncytial virus bronchiolitis. Thorax 1997; 52: 634-637.

9. Wainwright C, Altamirano L, Cheney M, et al. A multicenter, randomized, double-blind, controlled trial of nebulized epinephrine in infants with acute bronchiolitis. New Eng J Med 2003; 349: 27-35.

10. Boogaard R, Hulsmann AR, van Veen L, et al. Recombinant human deoxyribonuclease in infants with syncytial virus bronchiolitis. Chest 2007; 131: 788-795.

11. Nenna R, Tromba V, Berardi R, et al. Recombinant human deoxyribonuclease treatment in hospital management of infants with moderate-severe bronchiolitis. Eur J Inflamm 2009; 7: 169-174.

12. Zang L, Mendoza-Sassi RA, Wainwright C, et al. Nebulized hypertonic solution for acute bronchiolitis in infants (Review). Cochrane Database Syst Rev 2008; 8: CD006458.

13. Papoff P, Moretti C, Cangiano G, et al. Incidence and predisposing factors for severe disease in previously healthy term infants experiencing their first episode of bronchiolitis. Acta Paediatr 2011; 100: e17-e23.

14. Hall CB. Respiratory syncytial virus and parainfluenza virus. N Engl J Med 2001; 21: 1917-1928.

15. Xepapadaki P, Psarras S, Bossios A, et al. Human Metapneumovirus as a causative agent of acute bronchiolitis in infants. J Clin Virol 2004; 30: 267-270.

16. Jacques J, Moret $\mathrm{H}$, Renois $\mathrm{F}$, et al. Human Bocavirus quantitative DNA detection in French children hospitalized for acute bronchiolitis. J Clin Virol 2008; 43: 142-147.

17. Papadopoulos NG, Moustaki M, Tsolia M, et al. Association of rhinovirus infection with increased disease severity in acute bronchiolitis. Am J Respir Crit Care Med 2002; 165: 1285-1289.

18. Papadopoulos NG, Gourgiotis D, Javadyan A, et al. Does respiratory syncytial virus subtype influences the severity of acute bronchiolitis in hospitalized infants? Respir Med 2004; 98: 879-882. 
19. Semple MG, Cowell A, Dove W, et al. Dual infection of infants by human metapneumovirus and human respiratory syncytial virus is strongly associated with severe bronchiolitis. J Infect Dis 2005; 191: 382-386.

20. García-García ML, Calvo C, Pérez-Breña P, et al. Prevalence and clinical characteristics of human metapneumovirus infections in hospitalized infants in Spain. Pediatr Pulmonol 2006; 41: 863-871.

21. Marguet C, Lubrano M, Gueudin M, et al. In very young infants severity of acute bronchiolitis depends on carried viruses. PLoS One 2009; 4: e4596.

22. Midulla F, Scagnolari C, Bonci E, et al. Respiratory syncytial virus, human bocavirus and rhinovirus bronchiolitis in infants. Arch Dis Child 2010; 95: 35-41.

23. Fodha I, Vabret A, Ghedira L, et al. Respiratory syncytial virus infections in hospitalized infants: association between viral load, virus subgroup, and disease severity. J Med Virol 2007; 79: 1951-1958.

24. Gerna G, Campanini G, Rognoni V, et al. Correlation of viral load as determined by real-time RT-PCR and clinical characteristics of respiratory syncytial virus lower respiratory tract infections in early infancy. J Clin Virol 2008; 41: 45-48.

25. Purcell K, Fergie J. Concurrent serious bacterial infections in 912 infants and children hospitalized for treatment of respiratory syncytial virus lower respiratory tract infection. Pediatr Infect Dis J 2004; 23: 267-269.

26. Singh AM, Moore PE, Gern JE, et al. Bronchiolitis to asthma: a review and call for studies of gene-virus interactions in asthma causation. Am J Respir Crit Care Med 2007; 175: 108-119.

27. Witting HJ, Glaser J. The relationship between bronchiolitis and childhood asthma; a follow-up study of 100 cases of bronchiolitis. J Allergy 1959; 30: 19-23.

28. Martinez FD, Morgan WJ, Wright AL, et al. Diminished lung function as a predisposing factor for wheezing respiratory illness in infants. N Engl J Med 1988; 319: 1112-1117.

29. Young S, O'Keeffe PT, Arnott J, et al. Lung function, airway responsiveness, and respiratory symptoms before and after bronchiolitis. Arch Dis Child 1995; 72: 16-24.

30. Colasurdo GN, Hemming VG, Prince GA, et al. Human respiratory syncytial virus affects nonadrenergic noncholinergic inhibition in cotton rat airways. Am J Physiol 1995; 268: L1006-L1011.

31. Piedimonte $G$, Rodriguez MM, King KA, et al. Respiratory syncytial virus upregulates expression of the substance $P$ receptor in rat lungs. Am J Physiol 1999; 277: L831-L840.

32. Pala P, Bjarnason R, Sigurbergsson $F$, et al. Enhanced IL-4 responses in children with a history of respiratory syncytial virus bronchiolitis in infancy. Eur Respir J 2002; 20: 376-382.

33. Smyth RL, Fletcher JN, Thomas HM, et al. Respiratory syncytial virus and wheeze. Lancet 1999; 354: 1997-1998.

34. van Schaik SM, Welliver RC, Kimpen JL. Novel pathways in the pathogenesis of respiratory syncytial virus disease. Pediatr Pulmonol 2000; 30: 131-138.

35. Midulla F, Huang YT, Gilbert IA, et al. Respiratory syncytial virus infection of human cord and adult blood monocytes and alveolar macrophages. Am Rev Respir Dis 1989; 140: 771-777.

36. Panuska JR, Midulla F, Cirino NM, et al. Virus-induced alterations in macrophage production of tumor necrosis factor and prostaglandin E2. Am J Physiol 1990; 259: L396-L402.

37. Midulla F, Villani A, Panuska JR, et al. Respiratory syncytial virus lung infection in infants: immunoregulatory role of infected alveolar macrophages. J Infect Dis 1993; 168: 1515-1519.

38. Fjaerli HO, Farstad T, Rød G, et al. Acute bronchiolitis in infancy as risk factor for wheezing and reduced pulmonary function by seven years in Akershus County, Norway. BMC Pediatr 2005; 5: 31.

39. Noble V, Murray M, Webb MS, et al. Respiratory status and allergy nine to 10 years after acute bronchiolitis. Arch Dis Child 1997; 76: 315-319.

40. Sigurs N, Gustafsson PM, Bjarnason R, et al. Severe respiratory syncytial virus bronchiolitis in infancy and asthma and allergy at age 13. Am J Respir Crit Care Med 2005; 171: 137-141.

41. Sigurs N, Aljassim F, Kjellman B, et al. Asthma and allergy patterns over 18 years after severe RSV bronchiolitis in the first year of life. Thorax 2010; 65: 1045-1052.

42. Koponen P, Helminen M, Paassilta M, et al. Preschool asthma after bronchiolitis in infancy. Eur Resp J 2011. [Epub ahead of print: doi:10.1183/09031936.00040211].

43. Goksör E, Amark M, Alm B, et al. Asthma symptoms in early childhood--what happens then? Acta Paediatr 2006; 95: 471-478.

44. Piippo-Savolainen E, Korppi M. Wheezy babies-wheezy adults? Review on long-term outcome until adulthood after early childhood wheezing. Acta Paediatr 2008; 97: 5-11.

45. Guerra S, Wright AL, Morgan WJ, et al. Persistence of asthma symptoms during adolescence: role of obesity and age at the onset of puberty. Am J Respir Crit Care Med 2004; 170: 78-85.

46. Gern JE, Books GD, Meyer $P$, et al. Bidirectional interactions between viral respiratory illnesses and cytokine responses in the first year of life. J Allergy Clin Immunol 2006; 117: 72-78.

47. Regamey N, Kaiser L, Roiha HL, et al. Viral etiology of acute respiratory infections with cough in infancy: a community-based birth cohort study. Pediatr Infect Dis J 2008; 27: 100-105.

48. Kusel MM, de Klerk NH, Holt PG, et al. Role of respiratory viruses in acute upper and lower respiratory tract illness in the first year of life: a birth cohort study. Pediatr Infect Dis J 2006; 25: 680-686.

49. Jackson DJ, Gangnon RE, Evans MD, et al. Wheezing rhinovirus illnesses in early life predict asthma development in high-risk children. Am J Respir Crit Care Med 2008; 178: 667-672.

50. Kotaniemi-Syrjänen A, Vainionpää R, Reijonen TM, et al. Rhinovirus-induced wheezing in infancy-the first sign of childhood asthma? J Allergy Clin Immunol 2003; 111: 66-71.

51. Valkonen $\mathrm{H}$, Waris $\mathrm{M}$, Ruohola $\mathrm{A}$, et al. Recurrent wheezing after respiratory syncytial virus or non-respiratory syncytial virus bronchiolitis in infancy: a 3-year follow-up. Allergy 2009; 64: 1359-1365.

52. Midulla F, Pierangeli A, Cangiano G, et al. Rhinovirus bronchiolitis and recurrent wheezing: one year follow-up. Eur Resp J 2011. [Epub ahead of print: doi:10.1183/09031936.00188210].

53. Lehtinen P, Ruohola A, Vanto T, et al. Prednisolone reduces recurrent wheezing after a first wheezing episode associated with rhinovirus infection or eczema. J Allergy Clin Immunol 2007; 119: 570-575.

54. Gern JE, Busse WW. Association of rhinovirus infections with asthma. Clin Microbiol Rev 1999; 12: 9-18.

55. Einarsson 0, Geba GP, Zhu Z, et al. Interleukin-11: stimulation in vivo and in vitro by respiratory viruses and induction of airways hyperresponsiveness. J Clin Invest 1996; 97: 915-924.

56. Gern JE, Vrtis R, Grindle KA, et al. Relationship of upper and lower airway cytokines to outcome of experimental rhinovirus infection. Am J Respir Crit Care Med 2000; 162: 2226-2231.

57. Papadopoulos NG, Stanciu LA, Papi A, et al. A defective type 1 response to rhinovirus in a asthma. Thorax 2002; 57: 328-332. 